\title{
FUZZY LOGIC BASED BURNED SEVERITY CLASSIFICATION AND MAPPING WITH LANDSAT-8 DATA
}

\author{
Behzad Valipour Shokouhi ${ }^{1}$, Mehrdad Eslami ${ }^{2}$ \\ ${ }^{1}$ Department of Geography, Tartu University, Vanemuise St. 46, 51003, Tartu, Estonia - behzad.valipour@ut.ee \\ ${ }^{2}$ School of Surveying and Geospatial Engineering, University of Tehran, Tehran, Iran - meslami@ut.ac.ir
}

ICWG II/III: Pattern Analysis in Remote Sensing

KEY WORDS: Fuzzy Logic System, Supervised classification, Landsat 8, Support Vector Machine, Burn severity

\begin{abstract}
:
Wildfire has a strong effect on both land use and land cover so that every year, thousands of hectares of forests, farms, and urban infrastructure are destroyed. Mapping and estimation of damages are crucial for planning and decision making. The aim of this study is classification and mapping burn severity using multi-temporal Landsat data and well-known burn severity indices including Normalized Burn Ratio (NBR) and Burned Area Index (BAI) calculated for pre- and post- Landsat 8 images. Subtracted images such as dNBR (Difference Normalized Burn Ratio), RBR (Relativized Burn Ratio) and dBAI (Difference Burned Area Index) were produced on the bases of indices as classification input. Among classification methods, the fuzzy supervised classification was utilized with three classes. The result shows the strong performance of the Fuzzy Logic system (FLS) in the detection of the area with the limited number of training data so that the average accuracy of the classes is $85 \%$; plus, from the human logic perspective, the result was meaningful so that recognition of the features and changes visually were understandable.
\end{abstract}

\section{INTRODUCTION}

One of the man-made and natural disasters which cause the death of people, damage to residential areas and finally destruction of natural habitats is the wildfire. Each year forest fires take place around the world several times. Hence, monitoring and mapping these areas provide invaluable information to determine the amount of damage and burn severity and subsequent forest ecosystem management.

Burn severity is defined as ecological changes after wildfire which can be used to calculate the amount of the carbon released; as well as, the forest type was ruined (Soverel, Perrakis, and Coops 2010). One of the main methods for estimation of burn severity is the Composite Burn Index (CBI) measured on the ground (Key 2006; Mallinis, Mitsopoulos, and Chrysafi 2017). CBI determines the average condition of various factors to address the severity value of a plot (Key and Benson 2006). Research outcomes reveal that there is a close correlation between the CBI and spectral reflectance recorded by Remote Sensing (RS) sensors (Key and Benson 2006; Mallinis, Mitsopoulos, and Chrysafi 2017; Methods 2012; Miller et al. 2009; Parks, Dillon, and Miller 2014; Soverel, Perrakis, and Coops 2010); plus, the RS techniques are fast and cost-effective tool for this purpose (Lentile et al. 2006; Mallinis, Mitsopoulos, and Chrysafi 2017).

RS techniques have been utilized as critical tools for mapping, monitoring, prevention of forest fire in various scales since the mid-1980s (Chu and Guo 2014; Navarro, Caballero, et al. 2017). Different bands in Multispectral Imagery (MSI) makes it possible to analyze the area before and after the fire through RS indices (Epting, Verbyla, et al. 2005) including Normalized Difference Vegetation Index (NDVI) (Escuin, Navarro, et al. 2008), Normalized Burn Ratio (NBR) (Epting, Verbyla, et al. 2005; Key and Benson 2006) and Burned Area Index (BAI) (Kavzoglu, Erdemir, et al. 2016). Although all of them have correlation with fire severity (Mallinis, Mitsopoulos, et al. 2017), studies approved that NBR and its bi-temporal models such as the differenced Normalized Burn Ratio (dNBR), the
Relative differenced Normalized Burn Ratio (RdNBR), and the Relativized Burn Ratio (RBR) are much suitable with high accuracy (Mallinis, Mitsopoulos, et al. 2017). Also, studies indicated that some of the spectral bands are more suitable for mapping the wildfire including visible(VIS), near-infrared (NIR), mid-infrared (MIR) and thermal infrared (TIR) (Navarro, Caballero, et al. 2017).

One of the ways to achieve environmental information through RS imagery is classification (Zhang and Foody 2010). Due to mixed pixels, the classification of RS data often cannot provide the content result. The main reasons are 1) spatial resolution of images and 2) various types of a feature, such as vegetation type, in the area (Zhang and Foody 2010). That is, the conventional classification methods such maximum likelihood and Support Vector Machine cannot have appropriate performance and reduce the image classification accuracy (Zhang and Foody 2010). Fuzzy logic theory, propounded by Prof. Zadeh in 1965 (L. A. Zadeh, 1965), has been proven that can have higher accuracy compared to classical methods (Nedeljkovic, Vi, et al. 2004; Wang, Xu, et al. 2018; Zhang and Foody 2010).

Fuzzy logic system (FLS) has also been indicated is an appropriate tool for mapping forest fires. Angayarkkani (2009) used FLS to automated detection of forest fire using satellite images. More recently, FLS is used for calculation of forest fir risk as well (Garcia-jimenez, Jurio, et al. 2017). Bolourchi and Uysal (2013) employed FLS to detect forest fire in the initial stage before fast-moving.

The aim of this study is classification and mapping burn severity using multi-temporal Landsat data obtained from Sardinia island, Italy. For this purpose, well-known Normalized Burn Ratio (NBR) and Burned Area Index (BAI) were calculated for pre- and post-images. Subtracted images such as dNBR, RBR and dBAI were produced on the bases of indices as classification input. Among classification methods, the fuzzy supervised classification was utilized firstly, to decrease the influence of mixed pixels; secondly to increase the accuracy 
with the low number of training data.

\section{STUDY AREA, DATA AND TRAINING DATA}

\subsection{Description of Study area and wildfire information}

Sardinia island is the second largest island in the western Mediterranean Sea located between $38^{\circ} 51^{\prime}$ and $41^{\circ} 18^{\prime}$ latitude north and $8^{\circ} 8^{\prime}$ and $9^{\circ} 50^{\prime}$ east longitude. Its area is almost 24,100 square kilometres. Most parts of the island are covered by forest including Quercus ilex L., Quercus suber L., and Quercus pubescens Willd. At higher elevations, the oak formation merges with Castanea sativa Mill. and Ilex aquifolium L. The coniferous stands (Pinus spp.) are limited (3\%). Mediterranean maquis and garrigue covers $28 \%$ of the island (Ager et al. 2014). During the summer it is threatened by a forest fire. According to The European Forest Fire Information System (EFFIS), during the last five years, 1311 forest fire has happened in the study area, while 20 of them were major fires. These wildfires took place in different part of the island and damaged agriculture areas and urban infrastructures. The biggest one occurred on July 1st, 2016, and lasted for three days, and destroyed almost 4000 ha of Borore in Nuoro Province. (Figure 1)

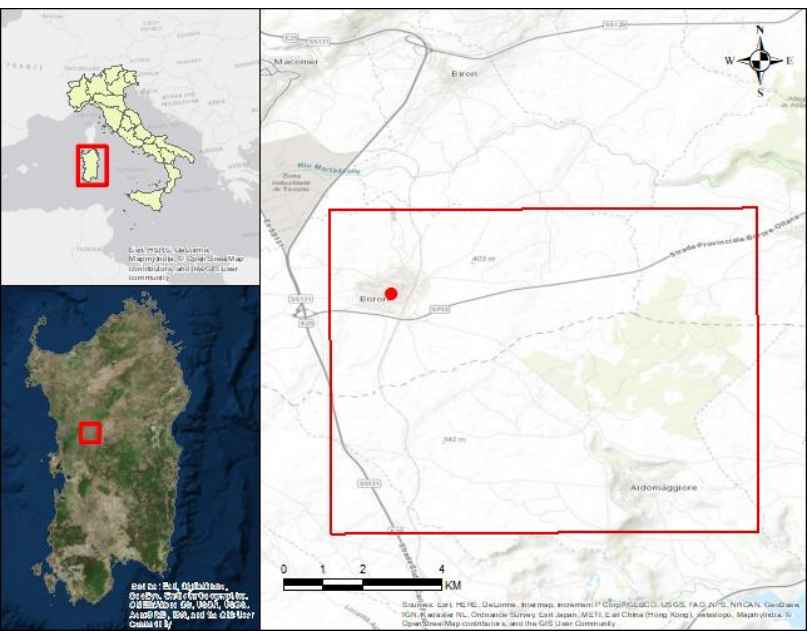

Figure 1: study area.

\subsection{Data}

In this study, Landsat-8 OLI images provided by the United States Geological Survey (USGS) was utilized. Landsat-8 OLI satellite with medium spatial resolution (30 meters), launched in 2013, includes 11 bands (Table 1). The important benefits of this satellite are free accessibility to data, the various spectral bands, coverage of entire the world, big dataset. Because of this, four level-1 images (pre-fire and post-fire, Table 2) were acquired to map the burnt areas.

The severity map of the forest fire for this area, produced using GeoEye and Pleiades-1A which are high-resolution Earth observation satellites, was collected from the Copernicus Emergency Management Service website (EMSR171 2016) and considered as a true source.

\begin{tabular}{|l|c|}
\hline \multicolumn{1}{|c|}{ Bands } & Wavelength $(\mu \mathrm{m})$ \\
\hline B1 - Ultra Blue & $0.435-0.451$ \\
B2 - Blue & $0.452-0.512$ \\
B3 - Green & $0.533-0.590$ \\
B4 - Red & $0.636-0.673$ \\
B5 - Near Infrared (NIR) & $0.851-0.879$ \\
B6 - Shortwave Infrared (SWIR) 1 & $1.566-1.651$ \\
B7 - Shortwave Infrared (SWIR) 2 & $2.107-2.294$ \\
B8 - Panchromatic & $0.503-0.676$ \\
B9 - Cirrus & $1.363-1.384$ \\
B10 - Thermal Infrared (TIRS) 1 & $10.60-11.19$ \\
B11 - Thermal Infrared (TIRS) 2 & $11.50-12.51$ \\
\hline
\end{tabular}

Table 1: Landsat-8 OLI satellite bands

\begin{tabular}{|c|c|}
\hline & Acquisition Date \\
\hline Pre-fire & $2016 / 06 / 15$ \\
\hline Post-fire & $2016 / 07 / 17$ \\
\hline
\end{tabular}

Table 2: pre-/post-fire images applied in this study

\subsection{Training data and classes}

The map provided with the Copernicus Emergency Management Service is comprised of four classes including Slight Damage (SD), Moderately damaged (MD), Highly Damaged (HD) and Completely Destroyed (CD). We have collected 279 training data proportional to the relative area of each class. After evaluation of the training data, it was noticed that there are some limitations. The low number of training data for SD and HD classes on one side, and limitation in the spatial, spectral resolution ( 30 meters and 11 bands, respectively) of Landsat imagery on the other side makes it difficult to separate these two classes from the others. This is because the training data comes from the map produced by very high resolution (VHR) imagery while the data used in this study have a moderate resolution. Hence, it makes that impossible to classify them into different classes. Therefore, the aforementioned classes were merged into one class called Moderately Damaged class (slightly to highly damaged). Finally, three classes including Unburned (UN), Moderately Damaged (MD) and Completely Destroyed (CD) classes were used.

\section{METHODOLOGY}

\subsection{Pre-Processing}

Atmospheric correction is one of the main steps to remove the effect of the atmospheric aerosol from the image; especially when images are acquired under the distinct conditions and are meant to be utilized in combination with each other. In this study, the atmospheric correction was performed by means of FLAASH (Fast Line-of-sight Atmospheric Analysis of Spectral Hypercubes) method in ENVI software for both pre- and postimages. 


\subsection{Subtracted Burnt Area Mapping Indices}

Normalized Burn Ratio (NBR) is a well-known index with high accuracy able to determine the burnt area; plus, the Burnt Area Index (BAI), proposed by Martin (1998) is another index to separate fire-affected area from others. Studies show BAI is suitable for the Mediterranean environment and has high distinction ability for the burnt area (Chuvieco and Palaciosorueta 2002). In this study subtraction of these two indices on the bases of pre- and post-images (dNBR, dBAI) were calculated to determine the severity of the fire. In addition to aforementioned subtracted indices, the Relativized Burn Ratio (RBR) is proved to have a higher accuracy compared to dNBR (Quintano, Fernández-Manso, and Fernández-Manso 2018) and provides appropriate accuracy in sparse coverage of vegetation (Parks, Dillon, and Miller 2014) was calculated. Given their ability in the determination of burn severity and area, these three subtracted indices were applied as input variables for Fuzzy Logic classification.

$$
\begin{aligned}
& \mathrm{NBR}=(\mathrm{NIR}-\mathrm{SWIR}) /(\mathrm{NIR}+\mathrm{SWIR}) \\
& \mathrm{BAI}=1 /\left((0.1-\mathrm{Red})^{2}+(0.06-\mathrm{NIR})^{2}\right) \\
& \mathrm{dNBR}=\mathrm{NBR}_{\text {pre-fire }}-\mathrm{NBR}_{\text {post-fire }} \\
& \mathrm{dBAI}=\mathrm{BAI} \text { pre-fire }-\mathrm{BAI} \text { post-fire } \\
& \mathrm{RBR}=(\mathrm{dNBR} /(\mathrm{NBR} \text { pre-fire }+1.001))
\end{aligned}
$$

\subsection{Classification}

Classification can be defined as categorization of whole pixels of a satellite imagery to produce the thematic map (Al-doski et al. 2013; Lillesand 1994). Classification approaches have increased over the years and they can be categorized in various ways. However, the well-known type is supervised and unsupervised classification. There are two sorts of uncertainties in RS imagery, uncertainties of pixel classes and classification decision. So non-parametric supervised classifications such as support vector machine (SVM) are not able to deal with uncertainties while Fuzzy Logic system (FLS) methods can overcome (Eslami, M., A. Mohammadzadeh 2015; Wang, Xu, and $\mathrm{Li}$ 2018). Thus, in this study, the FLS approach was utilized to classify and map the burn severity in three classes. Figure 2 displays the flowchart of the overall process of the study.

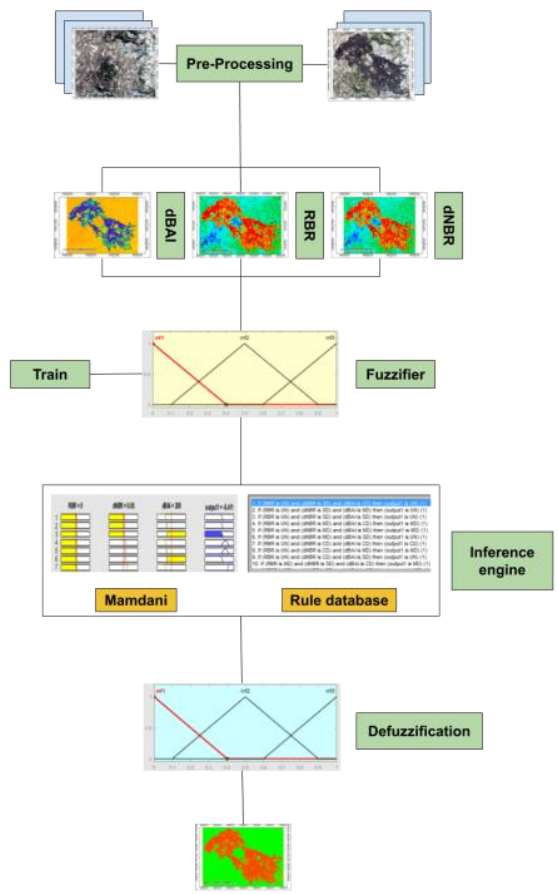

Figure 2. Flowchart summarizing the suggested processing of Classification

\subsection{Fuzzy Logic System}

The Fuzzy Logic System (FLS) uses the linguistic variable instead of the logic variable. Burrough in 1989 pointed that it is suitable to utilize FLS whenever there is an ambiguous state (Metternicht 1999) e.g., 'What is the threshold value accurately splitting areas of completely burned from moderate one?'. The basic structure of FLS includes fuzzification, inference, and defuzzification (Figure 2). FLS can have any values between 0 and 1 so that 0 means "completely not belong to a set" and 1 means "completely belongs to a set", and all values between them show the "degree of belonging to a set". This trend is implemented by membership function (MF) in the fuzzification step so that whole crisp inputs convert into fuzzy values. The most famous MF are triangular, trapezoidal and bell curves. In FLS, If-Then Rules are defined to specify different conditions of the output. The fuzzy rule is presented as the following form (Adopted from (Bolourchi and Uysal 2013)):

IF INPUT1 is F1 and INPUT2 is F2 ... and INPUTn is Fn THEN OUTPUT is $\mathrm{Yk}$

In the inference step, the results of If-Then Rules are combined to achieve the final output. The last step includes defuzzification where fuzzy outputs should be transformed into crisp ones.

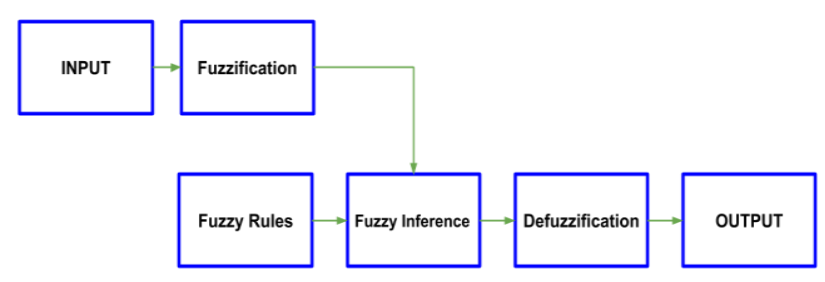

Figure 3. Fuzzy Logic System adopted from (L.-X. Wang 1999)

\section{RESULT AND DISCUSSION}

On the way of the classification procedure, three subtracted burnt area mapping indices were calculated. Figure 4 displays the computed imageries including RBR, dNBR and dBAI. These three indices were utilized as inputs for FLS classification.

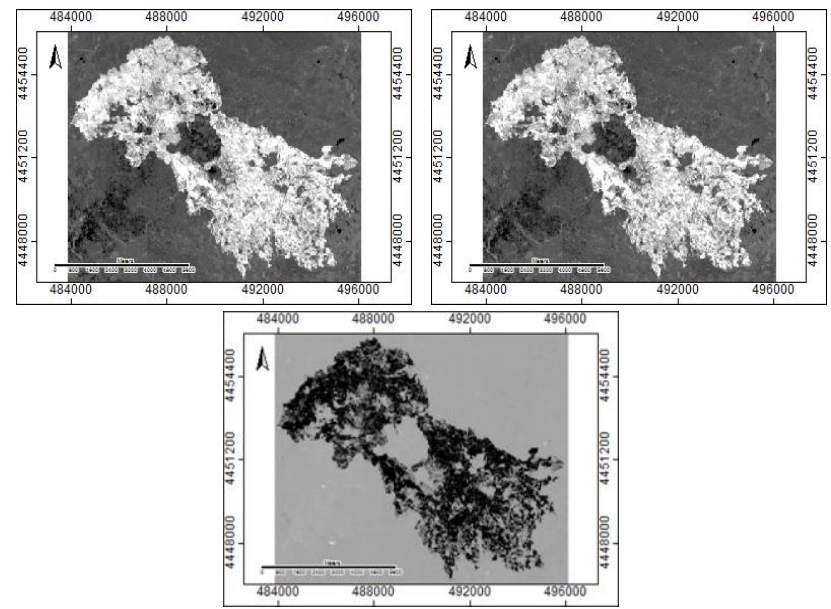

Figure 4. Calculated subtracted indices. RBR (a), dNBR (b), dBAI (c) 
Three classes were defined for the classification purpose including Unburned (UN), Moderately Damaged (MD) and Completely Destroyed (CD). Table 3 presents statistical information on the training data for the defined classes in different indices utilized for the design of FLS. Given that there was not any information regarding unburned areas in the provided map by ESM, training data was collected based on their conditions before and after wildfire visually.

\begin{tabular}{|ccccc|}
\hline \multicolumn{5}{|c|}{ dBAI (a) } \\
\hline Level & Mean & StDev & Variance & Median \\
HD & -177.16 & 108.955 & 11871.2 & -178.31 \\
MD & -27.258 & 27.9283 & 779.991 & -19.603 \\
\hline \multicolumn{5}{c}{ dNBR (b) } \\
\hline Level & Mean & StDev & Variance & Median \\
HD & 0.38726 & 0.14765 & 0.0218 & 0.39766 \\
MD & 0.09545 & 0.13938 & 0.01943 & 0.112 \\
\hline \multicolumn{5}{c}{ RBR (c) } \\
Level & Mean & StDev & Variance & Median \\
HD & 0.3267 & 0.11867 & 0.01408 & 0.3475 \\
MD & 0.0686 & 0.11625 & 0.01351 & 0.0874 \\
\hline
\end{tabular}

Table 3. Training dataset statistical variations: Differential Normalized Burn Ratio (a), the Relative Differenced Normalized Burn Ratio (b), and the Relativized Burn Ratio (c)

In the second step, the Fuzzy inference system was designed through Matlab's FLS Toolbox. For this purpose, the Mamdani method was used for inference system which is the common approach in various application due to its simple concepts (Bolourchi and Uysal 2013). The triangular function was utilized for fuzzification. On the bases of output expectation, the rules statements can be made so that in this study 27 rules were constructed.

After completion of the inference system, defuzzification was carried out to reach the last result. The appropriate thresholds were selected to interpret the burn severity of the area. Resulting image of classification is presented in Figure 5.

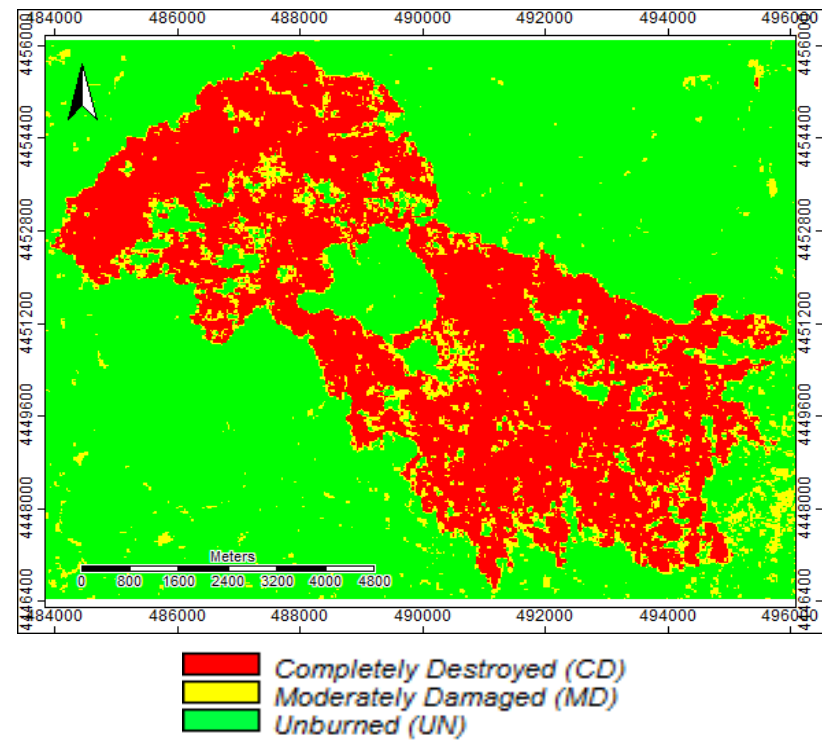

Figure 5. The result of FLS classification

Support Vector Machine (SVM) classification was carried out to compare the result with FLS classification. Figure 6 displays the result of this method. The purpose was to show the flexibility of FLS classification method; in addition, to compare the result with Support Vector Machine (SVM) classification which depends on the sufficient number of training data for the defined classes for analysis.

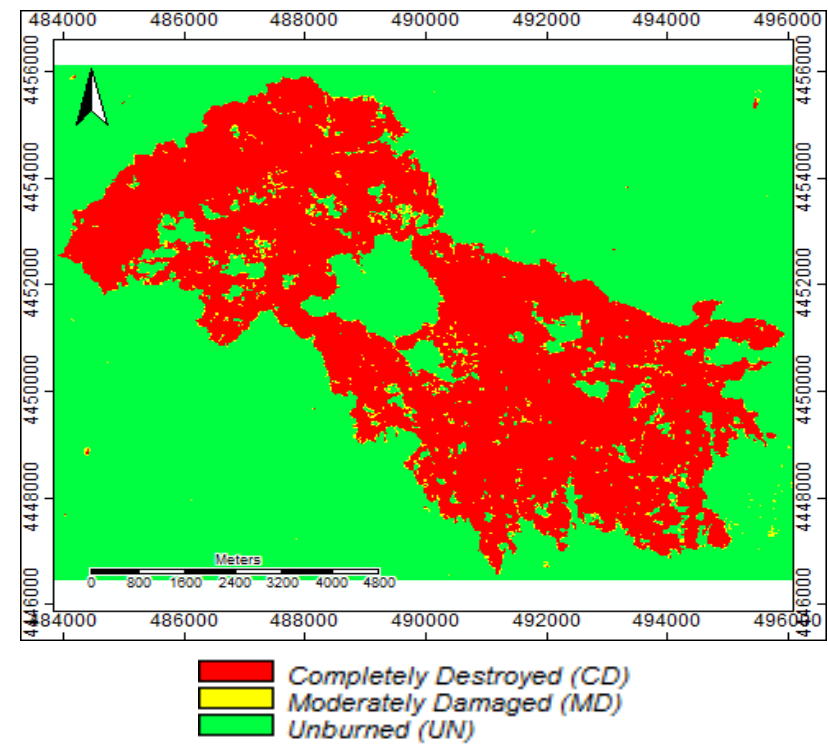

Figure 6. The result of SVM classification

\begin{tabular}{|l|l|}
\hline 1 & $\mathrm{IF}<\mathrm{RBR}$ is $\mathrm{UN}>\mathrm{AND}<\mathrm{dNBR}$ is $\mathrm{UN}>\mathrm{AND}<\mathrm{dBAI}$ is $\mathrm{CD}>\mathrm{THEN}<\mathrm{Class}$ is $\mathrm{UN}>$ \\
\hline 2 & $\mathrm{IF}<\mathrm{RBR}$ is $\mathrm{UN}>\mathrm{AND}<\mathrm{dNBR}$ is $\mathrm{UN}>\mathrm{AND}<\mathrm{dBAI}$ is $\mathrm{MD}>\mathrm{THEN}<\mathrm{Class}$ is $\mathrm{UN}>$ \\
\hline 3 & $\mathrm{IF}<\mathrm{RBR}$ is $\mathrm{UN}>\mathrm{AND}<\mathrm{dNBR}$ is $\mathrm{MD}>\mathrm{AND}<\mathrm{dBAI}$ is $\mathrm{CD}>\mathrm{THEN}<\mathrm{Class}$ is $\mathrm{MD}>$ \\
\hline 4 & $\mathrm{IF}<\mathrm{RBR}$ is $\mathrm{CD}>\mathrm{AND}<\mathrm{dNBR}$ is $\mathrm{UN}>\mathrm{AND}<\mathrm{dBAI}$ is $\mathrm{CD}>\mathrm{THEN}<\mathrm{Class}$ is $\mathrm{CD}>$ \\
\hline 5 & $\mathrm{IF}<\mathrm{RBR}$ is $\mathrm{CD}>\mathrm{AND}<\mathrm{dNBR}$ is $\mathrm{CD}>\mathrm{AND}<\mathrm{dBAI}$ is $\mathrm{CD}>\mathrm{THEN}<\mathrm{Class}$ is $\mathrm{CD}>$ \\
\hline 6 & $\mathrm{IF}<\mathrm{RBR}$ is $\mathrm{MD}>\mathrm{AND}<\mathrm{dNBR}$ is $\mathrm{MD}>\mathrm{AND}<\mathrm{dBAI}$ is $\mathrm{CD}>\mathrm{THEN}<\mathrm{Class}$ is $\mathrm{MD}>$ \\
\hline
\end{tabular}

Table 4. Some rules applied in the FLS classification 
What is noticeable in the classification result is that when it goes from unburned to completely burnt region, the moderate burnt region is located between them (Figure 6). That is, the result is logic since the intensity of fire should increase gradually. Moreover, such information can provide suitable information for decision-making; for example, the safe path for the penetration of wildfire.

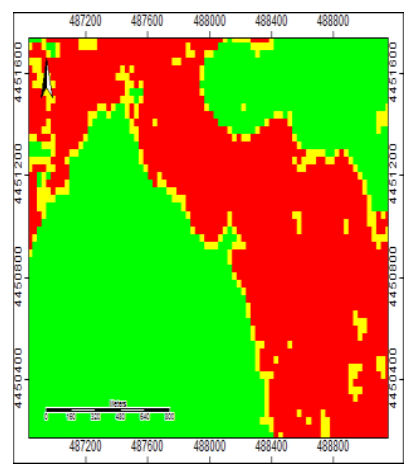

(a)

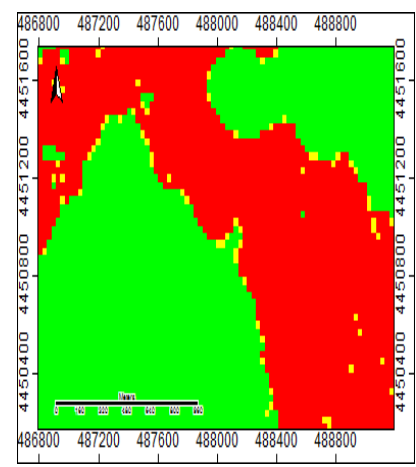

(b)
Figure 7. Changes in intensity of fire FLS (a) and SVM (b)

Another advantage of FLS classification compared to SVM is, it can detect MD class better. So it can be used to find the safe areas to construct campfire to stop a wildfire, or evaluation of damaged cost in details (Figure 8). However, it should be mentioned that both of them had good performance in detection of the unburned areas.

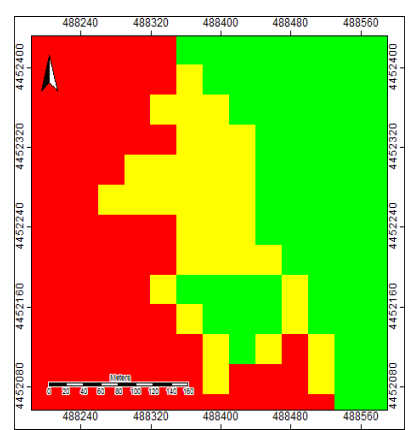

(a)

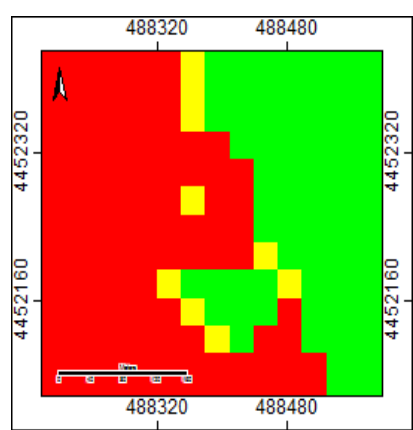

(b)
Figure 8. The performance of the two methods in detection of MD areas a) FLS b) SVM

FLS classification can also provide enough information with the low number of training data. For instance, the stream located in the study area was mapped by the FLS classification logically which shows the flexibility of the method. As figure 9 presents, the stream was classified as a low burnt class which is due to narrow width of the stream and strong effect of the adjacent high damaged areas, while SVM could not map it in a suitable way so it cannot be recognized.

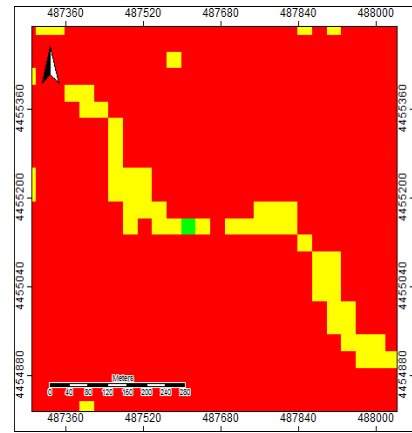

(a)

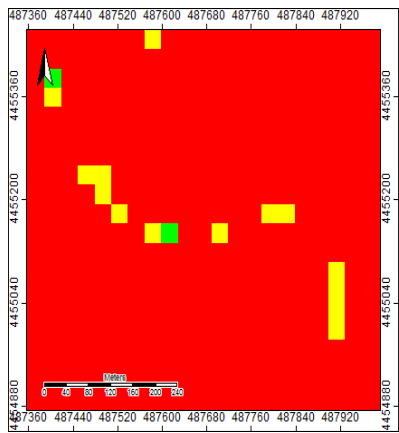

(b)
Figure 9. Differences in the mapping of the stream (a) FLS and (b) SVM

It should be considered that in the FLS classification, existing the burnt areas among unburnt ones (Figure 5.) are because of whether defective structure of the classifier, or proximity of statistical information of unburned and Moderate damaged classes; hence, error in the classification can be expected; however, add other input like NDVI (The normalized difference vegetation index) can be a solution to solve this problem.

Given that most parts of the region were completely damaged, the performance of SVM seems suitable to detect it visually; however, it could not provide logical details regarding the moderate damaged areas which can be due to lack enough training data, while FLS based on the rules defined by the experts can provide logical information.

For the purpose of accuracy evaluation of two approaches, confusion matrix for both results with two classes was calculated. Table 5 and Table 6 displays the confusion matrix for both FLS and SVM, respectively.

\begin{tabular}{|c|c|c|c|c|c|}
\hline \multicolumn{5}{|c|}{ Actual class } \\
\hline \multirow{4}{*}{$\begin{array}{c}\text { Predicted } \\
\text { class }\end{array}$} & Class & UN & MD & HD & Acc. \\
\cline { 2 - 6 } & UN & 2537 & 8 & 33 & $95.98 \%$ \\
& MD & 104 & 40 & 122 & $70.17 \%$ \\
& CD & 2 & 9 & 1260 & $89.04 \%$ \\
& Avg. Acc. & $85.06 \%$ & Overall Acc. & $93.24 \%$ \\
\hline
\end{tabular}

Table 5. Confusion matrix of Fuzzy Logic System Classification

\begin{tabular}{|c|c|c|c|c|c|}
\hline \multicolumn{6}{|c|}{ Actual class } \\
\hline \multirow{4}{*}{$\begin{array}{c}\text { Predicted } \\
\text { class }\end{array}$} & Class & UN & MD & HD & Acc. \\
\cline { 2 - 6 } & UN & 2626 & 27 & 43 & $99.35 \%$ \\
& MD & 9 & 13 & 29 & $22.81 \%$ \\
& CD & 8 & 17 & 1343 & $94.91 \%$ \\
& Avg. Acc. & $72.36 \%$ & Overall Acc. & $96.76 \%$ \\
\hline
\end{tabular}

Table 6. Confusion matrix of SVM Classification

As tables show, the overall accuracy of both the FLS and the SVM are suitable. However, the accuracy of the MD class in FLS with $70 \%$ is better than SVM with $22.81 \%$. Although CD class has high accuracy in SVM compared to FLS, it should be considered that provision of the logical map which shows 
details in each class understandably is more important than one class with high accuracy. On the other hand, the average accuracy of the classes in FLS with $85.06 \%$ is higher than SVM with $72.36 \%$ which indicate the suitability of the FLS method.

Based on the confusion matrix of FLS, it can be seen that the distribution of the pixels among the classes is normal so that only 2 pixels of UN class was located in the $\mathrm{CD}$, while it is not the same in the SVM especially in the MD and CD classes.

\section{CONCLUSIONS}

In this study, the burn severity has been mapped, using moderate resolution satellite imagery. Different indices such as dNBR, dBAI, and RBR, are estimated as classification feature space. Three main classes: unburned, MD and SD have been produced by Fuzzy supervised classification which has a close relation with human logic. The obtained results have been disclosed the functionality of the Fuzzy Logic System classification to produce burn severity map in comparison to SVM with the low number of the training data. As a result, there was approximately $50 \%$ difference between their accuracy in detection of MD class. In addition, the flexibility of FLS which comes from defined rules can be used to map objects comprehensibly. So, the produced thematic maps are visually logic. It is suggested to use fuzzy object-based approaches to increase mapping accuracy in future works.

\section{REFERENCES}

Ager, A.A., Preisler, H.K., Arca, B., Spano, D., Salis, M., 2014. Wildfire risk estimation in the Mediterranean area, Environmetrics, 25, pages 384- 396. doi.org/10.1002/env.2269.

Al-Doski, J., Mansorl, S. B., Shafri, H.Z.M., 2013. Image classification in remote sensing. Department of Civil Engineering, Faculty of Engineering, University Putra, Malaysia. Retrieved from https://www.iiste.org.

Angayarkkani, K., Radhakrishnan, N., 2009. Efficient forestfire detection system: a spatial data mining and image processing based approach. International Journal of Computer Science and Network Security, 9(3), 100-107. Retrieved from https://www.ijcsns.org.

Chu, T., Guo, X., 2014. Remote Sensing Techniques in Monitoring Post-Fire Effects and Patterns of Forest Recovery in Boreal Forest Regions: A Review. Remote Sensing, 6(1), 470-520. doi.org/10.3390/rs6010470.

Chuvieco, E., Martin, M.P., Palacios, A., 2002. Assessment of different spectral indices in the red-near-infrared spectral domain for burned land discrimination. International Journal of Remote Sensing, 2(23), 5103-5110. doi.org/10.1080/01431160210153129.

EMSR171. 2016. Copernicus Emergency Management Service (C) 2016 European Union), [EMSR171] Forest Fires in Sardinia,Borore: Grading Map.

Epting, J., David, V., Brian, S., 2005. Evaluation of Remotely Sensed Indices for Assessing Burn Severity in nterior Alaska Using Landsat TM and ETM+. Remote Sensing of Environment, 96(3-4), 328-39. doi.org/10.101 6/j.rse.2005.03.002.

Escuin, S., Navarro, R., Fernández, P., 2008. Fire Severity Assessment by Using NBR (Normalized Burn Ratio) and NDVI (Normalized Difference Vegetation Index) Derived from LANDSAT TM/ETM Images. International Journal of Remote Sensing,29(4), 1053-73. doi.org/10.1080/01431160701281072.

Eslami, M., Mohammadzadeh, A., Janalipour, M., 2015. Estimates of the Relative Changes of the Urmia Lake Using Fuzzy Classifier. ISSGE, 5(2), 119-30. Reterived from http://www.jgst.issge.ir/.

Garcia-jimenez, S., Aranzazu, J., Pagola, M., De Miguel, L., Barrenchea, E., Bustince, H., 2017. ForestFire Detection: A Fuzzy System Approach Based on OverlapIndices. Applied Soft Computing Journal, 52, 834-42. doi.org/10.1016/j.asoc. 2016.09.041.

Kavzoglu, T., Erdemir, M.Y., Tonbul, H., 2016. Evaluating performances of spectral indices for burned area mapping using object-based image analysis. Proceedings of Spatial Accuracy; Bailly, J.-S., Griffith, D., Josselin, D., Eds, 162-168. Retrieved from http://spatial-accuracy.org.

Key, C.H., Benson, N.C., 2006. Landscape assessment (LA). In: Lutes, Duncan C.; Keane, Robert E.; Caratti, John F.; Key, Carl H.; Benson, Nathan C.; Sutherland, Steve; Gangi, Larry J. 2006. FIREMON: Fire effects monitoring and inventory system. Gen. Tech. Rep. RMRS-GTR-164-CD. Fort Collins, CO: US Department of Agriculture, Forest Service, Rocky Mountain Research Station. p. LA-1-55, 164. Retrieved from https://www.fs.usda.gov.

Lentile, L.B., Holden, Z.A., Smith, A.M.S., Falkowski, M.J., Hudak, A.T., Morgan, P., Lewis, S.A., Gessler, P.E., Benson, N.C., 2006. RemoteSensing Techniques to Assess Active Fire Characteristics and Post-Fire Effects. International Journal of Wildland Fire, 15(3), 319-45. doi.org/10.1071/WF05097.

Lillesand, T., Kiefer, R. W., Chipman, J., 2015. Remote sensing and image interpretation. John Wiley \& Sons.

Mallinis, G., Mitsopoulos, I., Chrysafi, I., 2017. Evaluating and Comparing Sentinel 2A and Landsat-8 Operational Land Imager (OLI) Spectral Indices for Estimating Fire Severity in a Mediterranean Pine Ecosystem of Greece. GIScience and Remote Sensing, 55(1), 1-18. doi.org/10.1080/15481603.2017. 1354803.

Cansler, C.A., McKenzie, D., 2012. How robust are burn severity indices when applied in a new region? Evaluation of alternate field-based and remote-sensing methods. Remote sensing, 4(2), 456-483. doi.org/10.3390/rs4020456

Metternicht, G., 1999. Change detection assessment using fuzzy sets and remotely sensed data: an application of topographic map revision. ISPRS Journal of Photogrammetry and Remote Sensing, 54(4), 221-233. doi.org/10.1016/S09242716(99)00023-4

Miller, J.D., Knapp, E.E., Key, C.H., Skinner, C.N., Isbell, C.J., Creasy, R.M., Sherlock, J.W., 2009. Calibration andvalidation of the relative differenced Normalized Burn Ratio (RdNBR) to three measures of fire severity in the Sierra Nevada and 
Klamath Mountains, California, USA. Remote Sensing of Environment, 113(3), 645-656. doi.org/10.1016/j.rse.2008.11. 009

Navarro, G., Caballero, I., Silva, G., Parra, P., Vázquez, Á., Caldeira, R., 2017. Evaluation of Forest Fire on Madeira Island Using Sentinel-2A MSI Imagery. International Journal of Applied Earth Observationand Geoinformation, 58, 97-106. doi.org/10.1016/j.jag.2017.02.003

Nedeljkovic, I., 2004. Image classification based on fuzzy logic. The International Archives of the Photogrammetry, Remote Sensing and Spatial Information Sciences, 34(30), 3-7.

Quintano, C., Fernández-Manso, A., Fernández-Manso, O. 2018. Combination of Landsat and Sentinel-2 MSI Data for Initial Assessing of Burn Severity. International Journal of Applied Earth Observation and Geoinformation, 64, 221-25. doi.org/10.1016/j.jag.2017.09.014.

Nicholas, O.S., Perrakis, D.D.B., Coops, N.C., 2010. Estimating Burn Severity from Landsat DNBR and RdNBR Indices across Western Canada. Remote Sensing of Environment,114(9), 1896-1909. doi.org/10.1016/j.rse.2010. 03.013.

Wang, C., Xu, A., Li, X., 2018. Supervised Classification High-Resolution Remote-Sensing Image Based on Interval Type-2 Fuzzy Membership Function. Remote Sensing, 10(5), 710. doi.org/10.3390/rs10050710

Zhang, J., Foody, G.M., 1998. A fuzzy classification of sub-urban land cover from remotely sensed imagery. International journal of remote sensing, 19(14), 2721-2738. doi.org/10.1080/014311698214479

Wang, L.X., 1999. A course in fuzzy systems. Prentice-Hall press, USA. 